\title{
Value systems as motivational forces for the suppression of ageism towards older people amongst young adults: an analysis across countries
}

\author{
Adrian Stanciu ${ }^{1}$ (D) \\ ${ }^{1}$ Institute for Gerontology, Vechta University, Vechta, Germany \\ Email: adrian.stanciu@uni-vechta.de
}

(Accepted 25 August 2020; first published online 23 September 2020)

\begin{abstract}
What explains ageism towards older people? Several answers exist in the literature, but it is still unclear whether the ageism people express has been altered by motivational forces (i.e. factors which carry or enact motivation, leading to action or thought) or whether an original, primal ageism can be expressed directly. Investigating populations of young adults (45 and younger), this article suggests that value systems are sources of internal and external motivational forces which work to either suppress or to justify both subtle and blatant forms of ageism. It was hypothesised that, at the individual level, values precede any threat perception and negative stereotypical beliefs associated with older people, leading to forms of ageism which match the motivational goals of a person's values. It was further expected that, at the cultural level, values represent the climate in which people express ageist beliefs. It was found that self-transcendence values can bypass the negative effects of threat perception and negative stereotypes, resulting in less-negative forms of ageism. A sample comprising a clear majority of hierarchical, non-Western cultures showed that self-enhancement values also contributed motivational strength for the suppression of blatant ageism. A practical implication of these findings is the possibility of further developing existing strategies of combating ageism by working to effect appropriate long-term changes in the values of young adults.
\end{abstract}

Keywords: ageism; Justification-Suppression Model; value systems; threat perception; stereotypes; hierarchical and egalitarian cultures

\section{Introduction}

Ageism is defined as both negative and positive stereotypes, as well as prejudice and/ or discrimination, either against or to the advantage of people, on the basis of their chronological or perceived age (Iversen et al., 2009). It can be directed towards 
younger people, and can impact, for example, their processes of development and access to the job market (Abrams et al., 2011). It can also be directed towards older people. This form affects not only the psychological and physiological health of the older people themselves but also has consequences for younger people, as they can internalise ageism-related beliefs and behaviours into self-descriptions (Cuddy et al., 2005; Levy, 2009; North and Fiske, 2012, 2013; Lamont et al., 2015; Voss et al., 2018; Chang et al., 2020). In rapidly ageing societies, ageism towards older people is at least as pervasive and perhaps more detrimental than ageism towards younger people. After all, population ageing is a relatively recent development in the history of humankind, and our society is largely unprepared to accommodate growing proportions of older people. This paper addresses variations in ageism towards older people (hereinafter, simply 'ageism') held by younger people.

We are only beginning to understand the causes of ageism in a holistic manner (for a very recent review, see Marques et al., 2020). It is still unclear how, for instance, that despite being socially undesirable, ageism remains alive and widely acted upon in the labour market, in the health sector, and across almost every circumstance involving interactions between older and younger people. This article proposes an explanation of ageism based on the Justification-Suppression Model of prejudice (Crandall and Eshleman, 2003). The content of an individual's genuine (original, primal) ageism can be altered (managed, scrutinised)-before it is expressed - by internally and externally motivated attempts to suppress and justify it. This article examines whether value systems (Schwartz, 2006, 2012) represent sources of motivation for the suppression and justification of subtle and blatant ageism (Pettigrew and Meertens, 1995) shown by younger people (45 and younger) towards older people (70 and older). In two empirical studies based on multinational datasets (European Social Survey (ESS) and World Value Survey (WVS)), a multilevel analytical approach was taken, and it was expected that threat perception and stereotypes will mediate the effects of value preferences on ageism.

\section{Extant perspectives in explaining ageism}

This section provides an overview of the existing approaches to explaining ageism (for reviews, see North and Fiske, 2012; Bergman, 2017; Voss et al., 2018; Marques et al., 2020). These explanatory perspectives can be grouped into six categories: developmental, structural, cultural, intergenerational, socio-cognitive and individual.

The developmental approach suggests that ageism first emerges in childhood when children organise their surrounding environments into categories which help them navigate subsequent situations (Montepare and Zebrowitz, 2002; Bigler and Liben, 2006). During this phase, children also supply such categories with relevant content, which, in this case, may include stereotypes, prejudice and discrimination towards older people.

The structural explanation holds that there is a natural competition between social groups which leads to tensions between members of different groups (Vauclair et al., 2014; North and Fiske, 2015). Typically, older people are weakly competitive as a result of factors such as age-appropriate lower physical and cognitive ability (Cuddy et al., 2005). Older people also have a lower status in society, which is related to, amongst other issues, their departure from the job market. Other members of 
society interpret and generalise stereotypical traits (warmth and incompetence) from older people's competitiveness and status. These stereotypical traits then cause prejudice and discrimination against older people (Voss et al., 2018).

The cultural explanation is that structural aspects of society manifest in the content of local culture. Culture is a normative value system which is latent and at the core of all societal institutions which organise, educate and guide individual members of society (Schwartz, 2014). Older people can be seen and treated differently by different societies and cultures. Ageism is less of an issue in modernised societies (Vauclair et al., 2014), for example, or in societies with a greater proportion of older people still in the workforce (Bowen and Skirbekk, 2013). Furthermore, local traditions which emphasise the needs of the individual as opposed to the collective are cited as causing greater ageism in Western cultures than in Eastern ones (Löckenhoff et al., 2009; but see North and Fiske, 2015).

The intergenerational approach holds that there is a pool of increasingly scarce societal resources for which younger and older individual members of society all strive (North and Fiske, 2012, 2013). Extended longevity enabled by advancing technology and health developments creates an imbalance in the intergenerational succession to economic, political and social resources. Younger people feel threatened, believing that their access to these resources will be limited because, for example, older people will continue to be active politically and will thus 'complicate' the attitudes of newer generations. Ageism arises when younger people seek to maintain existing boundaries between the young and the old.

The socio-cognitive perspective holds that ageism is content imprinted in the minds of people and that culture is the culprit (Levy and Banaji, 2002; Levy, 2009; Bergman, 2017). For instance, the representation of older people in media outlets as frail and dependent individuals is a piece of cultural content which propagates ageism (Kessler and Schwender, 2012). Adolescents, adults and even older people harbour beliefs, feelings and behavioural tendencies which are biased against older people to a degree which depends on the content of their cultures. Culturally learned ageism is generally latent in people's minds and becomes activated and retrieved in specific circumstances (Levy, 2009; Lamont et al., 2015). This perspective is also applicable to immigrants, who may be confronted in their host cultures with novel expressions of ageism which they may incorporate into their pre-existing beliefs of older people and old age (Stanciu and Vauclair, 2018).

Finally, explanations have also been proposed at the individual level (for a review, see Lev et al., 2018). For one, age is a trait with which individuals may identify. Social identity theory (Tajfel and Turner, 1979) predicts that people who identify as young will seek to maintain their belonging to that age group by means of exclusion or aggression directed against people who are (or who identify as) old. Ageism is an identity process by which young individuals maximise their selfesteem. Another explanation is rooted in terror management theory (Greenberg et al., 1986), which posits that, in the wake of the looming threat of death, people seek to maintain stable self-esteem by endorsing appropriate world beliefs. Older people and old age are reminders of the frailty of human nature and the fact that death, bodily degradation and loss of societal relevance are inescapable (Martens et al., 2005). In this theory, ageism thus represents an attempt to escape psychologically from the terror of death. 


\section{A value-based model of the justification and suppression of prejudice}

There is currently no straightforward explanation for the ubiquity of ageism in contexts in which norms and policies are substantially anti-ageist (for a discussion on anti-ageism, see Ayalon and Tesch-Römer, 2018; also see the section above). One reason for this is that the literature on ageism is insufficiently equipped in terms of theory. This article proposes to draw parallels to other forms of 'isms' (racism and sexism) and to apply the findings of that research to the study of ageism. Racism and sexism as well as ageism ultimately refer to biased perceptions, beliefs and action which are either against or to the advantage of people on the basis of their characteristic traits. A theoretical framework which is capable of explaining all forms of 'isms', even in contexts of substantial anti- 'ism' norms, is the Justification-Suppression Model of prejudice (Crandall and Eshleman, 2003). The Justification-Suppression Model is applicable not only to the affective dimension (prejudice) but also to the cognitive and behavioural dimensions (stereotypes and discrimination, respectively) (also see Pereira et al., 2010).

Crandall and Eshleman (2003) define prejudice as any negative evaluation accompanied by an emotional reaction towards a person's traits and group memberships. They trace the roots of prejudice to the time when an individual first acquires prejudicial ideas, which they call genuine, primal or unaltered prejudice. This can happen during early socialisation (also see the developmental explanation above) as well as during the process in which a person adapts to a new culture (Stanciu and Vauclair, 2018). In the course of life, genuine prejudice is subjected to a process of suppression and/or justification before it is expressed in public or in psychological research. Suppression is the effort to reduce the expression or awareness of prejudice and serves the function of maintaining a sense of being a non-prejudiced self. Justification, on the other hand, is the process which leads a person to express an otherwise suppressed prejudice; it seeks to undo the effects of suppression. The expressed, verbalised or observable prejudice is therefore the prejudice which 'escapes' the suppression forces. Sources of motivation to suppress and justify prejudice are multiple and can derive from internal or external influences. Value systems are a major source for the motivational drive to suppress and justify prejudice (Crandall and Eshleman, 2003).

The Schwartz value theory is the state of art in researching human values (Schwartz, 2012; Borg et al., 2015). The theory holds that values are woven into the self-concept of individuals - they are beliefs linked with affect and refer to desirable goals which people are motivated to pursue. Values are context-independent and represent standards on which people base how they approach the way they interact with their surrounding environment. There are ten universal values: universalism (UN), benevolence (BE), conformity (CO), tradition (TR), security $(\mathrm{SE})$, power (PO), achievement (AC), hedonism (HE), stimulation (ST) and selfdirection (SD). Each has relations of incompatibility-compatibility with the other values according to underlying motivational goals. For instance, BE and AC are incompatible because the goal of the former is the welfare of others, while the goal of the latter is personal success. All ten values may be further collapsed on to a two-dimensional, higher-order structure which describes people's core goals and motivations in terms of openness to change, conservation, self-transcendence 
and self-enhancement. Openness to change (HE, ST and SD) refers to pursuing desired intellectual and emotional interests regardless of the difficulty or novelty of one's situation. Conservation (CO, TR and SE) is the opposite of openness to change, in that it invokes a preference for maintaining the status quo. Self-transcendence (UN and $\mathrm{BE}$ ) refers to promoting the wellbeing of others while transcending one's own selfish interests. Self-enhancement (AC and PO), on the other hand, involves pursuing one's own interests even at the expense of others.

Of the higher-order values (HOVs), the dyad self-transcendence (S-TR) versus self-enhancement (S-EN) is most likely to influence the justification and suppression of genuine prejudice. For instance, Feather and McKee (2011) showed, in a study conducted in Australia, that social-dominance orientation and racism were positively correlated with values of S-EN but negatively with values of S-TR. A study done in Italy found that adolescents who scored low on a measure of blatant and subtle ethnic prejudice preferred S-TR values compared to adolescents with high scores who preferred S-EN values (Falanga et al., 2015). Another study, based in the United States of America (USA), showed that S-TR predicted lower prejudice towards black people (Florez et al., 2019).

Value systems also contain cultural values. Schwartz (2006) proposed a subsequent theory wherein cultural values represent societal solutions to three challenges of living together: determining how to maintain a balance between the needs of the self and of the group, the best way to relate to the surrounding environment and natural landscape, and how to guarantee that individual members of society will act according to its rules. Of the three, the latter specifies two ways of collectively organising for the preservation of the social order in society. On the one hand, there are egalitarian societies which emphasise equality and co-operation. On the other, there are hierarchical societies which legitimise the unequal distribution of resources and emphasise personal over collective success.

Crandall and Eshleman (2003) anticipated the role of egalitarianism (EGAL) versus hierarchy (HRCHY) in the suppression and justification of prejudice, but they were ambiguous regarding the level at which the two operate. Schwartz (2006) analysed data from several countries and showed that EGAL rather than HRCHY was strongly correlated at the level of culture with non-homophobic attitudes $(r=0.63)$. Recently, Van Berkel et al. (2015) showed in a series of experimental studies that hierarchical values require less of a thoughtful process than egalitarian values, which makes them the primal motivational force in human interaction. According to Van Berkel et al. (2015), only through a sustained process of learning can egalitarian values truly disrupt or suppress prejudice.

\section{The present research}

A value-based model of the justification and suppression of ageism in younger populations from several countries is tested using data from two large, multinational surveys concerning the state of affairs in several European countries (ESS Round 4 (ESS-4), 2008) along with countries from all other continents (WVS Round 6 (WVS-6); Inglehart et al., 2014). The ESS and WVS are the result of a multinational collaborative project which ensures instrument equivalence (including questionnaire translations) and data quality across all participating 
countries. The resulting datasets are representative of each country with respect to (amongst other issues) individuals' values and their threat perception, stereotypes and ageism concerning older people. Subtle (indirect, covert) and blatant (direct, overt) forms of ageism (Pettigrew and Meertens, 1995) are examined. The subtle forms are expressed as negative affect. The blatant forms are expressed as rejection directed towards members of the older population.

There are several reasons why younger people might hold ageist beliefs. On the one hand, they may feel that their position, succession and access to societal resources is threatened by the presence of the older generations. On the other hand, the existing negative cultural beliefs and socio-structural reality were imprinted in their minds in childhood with the consequence that they now have latent stereotypical beliefs about older people which are negative and operate subconsciously. The relationship between threat perception and stereotypes may predict ageism in younger people (Crandall et al., 2011; Bahns, 2015). This study is based on the intergenerational explanation. It differentiates between threat perceptions which arise in younger people in response to expectations concerning older people's (alleged) economic intentions, on the one hand, and their succession intentions, on the other. It is expected that both of these indicators of threat perception will act negatively on younger people's ageism (Hypothesis 1). Based on the socio-cultural explanation, the study distinguishes between warmth and competence as two possible stereotypical traits which younger people may associate with older people. It is predicted that negative stereotypes regarding both traits will predict greater ageism in younger people (Hypothesis 2).

Subsequently, it is expected that the values of the individual and of the culture where the individual lives will predict ageism in younger people. Concerning the values of the individual, it is expected that S-TR will predict lower levels of ageism and that S-EN will predict higher levels of ageism (Hypothesis 3). Regarding cultural values, it is predicted that there will be lower levels of ageism in countries with higher levels of EGAL but higher levels of ageism in countries with higher levels of HRCHY (Hypothesis 4).

Lastly, it is expected that S-TR will act as a motivational force for the suppression of ageism and S-EN as a motivational force for justifying its expression. Stereotypes (especially the negative ones) are a consequence of perceived threat. One can thus think of a mediation link wherein values predict threat perceptions, which then predict stereotypes, which in turn predict ageism (see Figure 1). In sum, the total indirect effect on ageism resulting from threat perception and stereotype content will be positive for S-TR (Hypothesis 5) and negative for S-EN (Hypothesis 6).

\section{Study 1}

Study 1 examines the present hypotheses in samples of younger people across several European countries. The study uses the ESS-4 dataset, which contains information from 29 participating countries (Belgium, Bulgaria, Croatia, Cyprus, Czech Republic, Denmark, Estonia, Finland, France, Germany, Greece, Hungary, Ireland, Israel, Latvia, The Netherlands, Norway, Poland, Portugal, Romania, Russia, Spain, Slovakia, Slovenia, Sweden, Switzerland, Turkey, Ukraine and United Kingdom (UK)) and includes a total of $\mathrm{N}=56,752$ participants (mean 


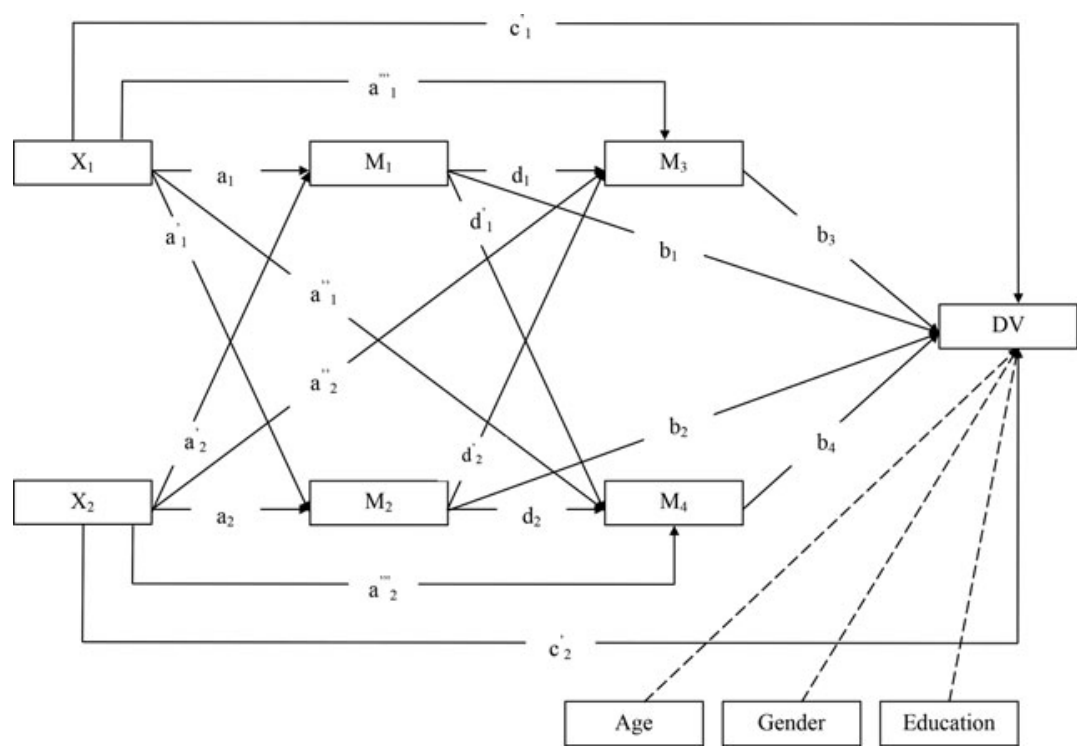

Figure 1. Direct effects are depicted. Letter a (with the associated subscripts and superscripts) depicts effects of predictors (X1 and $\mathrm{X} 2$ ) onto mediators (M1-M4). Letter $b$ (with the associated subscripts) depicts effects of mediators (M1-M4) onto the dependent variable. Letter c' (with the associated subscripts) depicts effects of predictors onto the dependent variable. Letter $d$ (with the associated subscripts and superscripts) depicts effects of proximal mediators (M1 and M2) onto distal mediators (M3 and M4). Interrupted lines depict effects ofcovariates onto the dependent variable.

Notes: $\mathrm{X}_{1}$ : self-transcendence. $\mathrm{X}_{2}$ : self-enhancement. $\mathrm{M}_{1}$ : threat: consumption. $\mathrm{M}_{2}$ : threat: succession. $\mathrm{M}_{3}$ : stereotype: warmth. $\mathrm{M}_{4}$ : stereotype: competence. DV: dependent variable.

age $=47.54$, standard deviation $(S D)=18.50$, range $=15-123)$. The dataset encapsulates a set of countries which, despite their geographical proximity, are quite heterogeneous in terms of culture, religion, economics and politics (Schwartz, 2006). The existing literature discusses several peculiarities concerning older people across the countries (for a review, see Swift et al., 2018). For instance, the stereotype of older people's competencies differs amongst countries with differing percentages of older people active in the workforce (Bowen and Skirbekk, 2013), while the subjective status of older people differs as a function of levels of modernisation (Vauclair et al., 2014). Although extensive research has been conducted using this dataset, no previous study has used it to test the role of values of younger people in suppressing and justifying their ageism.

\section{Method}

Data and analytical strategy

Only study participants aged 45 and younger were selected $(\mathrm{N}=26,885$; mean age $=31.13, \mathrm{SD}=8.60)$. Data were missing only at the first level of analysis. Pairwise deletion was applied; due to model complexity, the estimation of missing data in multiple imputations (full information maximum likelihood) resulted in model non-identification. The size of the valid datasets used for each model estimation 
can be found in the respective result tables (see Results). The dataset contains information on both subtle and blatant forms of ageism (see Measurement).

The data structure was hierarchical, with study participants (level 1) clustered in countries (level 2). Of the total variance, 4.3 per cent (subtle ageism) and 9.4 per cent (blatant ageism) were due to country differences. Unbiased estimates were obtained by statistically modelling the variance in the dependent variable in a part caused by individual differences and another caused by country differences. Multilevel analyses were conducted with Mplus.8 (Muthén and Muthén, 2017), while regression coefficients and the associated confidence intervals were estimated with the Bayesian approach (Markov chain Monte Carlo chains $=8$, iterations $i=$ 5,000).

Three statistical models were estimated after group-mean centring level-1 variables and grand-mean centring level-2 variables. First, all the study covariates at their respective level of analysis were introduced. Second, all the predictors and mediators were introduced without modelling the mediating effects. Third, the mediating effects at the individual level of analysis (see Figure 1) were modelled. Statistical significance (including that of the indirect effects) was evaluated based on the bootstrapped confidence intervals (Shrout and Bolger, 2002). Regression coefficients whose confidence intervals did not include zero were deemed significant at $\alpha=95$ (equivalent to $p<0.05$ ) per cent or at $\alpha=99$ (equivalent to $p<$ 0.01) per cent (Muthén and Asparouhov, 2012).

\section{Measurement}

Ageism. Subtle ageism was assessed using the survey item $(0=$ extremely negative, $10=$ extremely positive): 'And overall, how negative or positive do you feel towards people over 70?' Blatant ageism was assessed with the item $(0=$ completely unacceptable, $10=$ completely acceptable): 'And please tell me how acceptable or unacceptable you think most people in [e.g. Germany] would find it if a suitably qualified 70-year-old were appointed as their boss?'

Value systems. S-EN and S-TR were measured with the PVQ-21 instrument (Schwartz, 2003), which asks for similarities with a fictitious individual described in terms of how important each of 21 life-domains are to him/her $(1=$ very much like me, $6=$ not like me at all). Each of the 21 descriptions represent value-items which pertain to one of the ten basic human values and consequently one of the four higher-order value priorities. An example is: 'It is important to him/ her to be rich. He/she wants to have a lot of money and expensive things.' Four items made up S-EN: being rich, respected, admired and successful (item reliability, $\alpha=0.75)$. Five items made up S-TR: equal opportunities, respect for diversity, caring for the environment, helping other people and loyalty (item reliability, $\alpha=$ 0.74). S-EN and S-TR were computed as follows: (a) each value-item was reverse coded, (b) the scale measurement of each value-item was then corrected using the MRAT procedure (the individual average over all items was subtracted from each value-item), and (c) the mean value of the corrected value-items (of four and five items, respectively) was computed for each individual participant. Country coefficients for EGAL and HRCHY were readily available (Schwartz, 2008; see Table S1 in the online supplementary material). 
Threat perception. Threat perception was measured in the health and economic domains, which correspond to North and Fiske's (2013) prescriptions regarding consumption and succession. Perception of threat in the health sector (interchangeably, threat perception concerning consumption) was measured with the item $(0=$ no burden, $10=$ a great burden): 'Using this card, please tell me whether or not you think people over 70 are a burden on [e.g. Germany]'s health service these days?' Perception of threat in the economic sector (interchangeably, threat perception concerning succession) was measured with the item $(0=$ contribute very little economically, $10=$ contribute a great deal economically): 'All things considered, do you think people over 70 contribute a little or a great deal economically to [e.g. Germany] these days?'

Stereotypes. The stereotypes assessed were participants' meta-beliefs about the warmth and competence of people aged over 70 (Cuddy et al., 2005). The assessment of each stereotype dimension was done using a single item $(0=$ not at all likely to be viewed that way, $4=$ very likely to be viewed that way): 'Please tell me how likely it is that most people in [e.g. Germany] view those over 70 as friendly [competent]?'

Covariates. Three covariates at the individual level of analysis (level 1) were included: chronological age was self-reported in years; gender was self-assessed as male or female; education level was self-reported in completed years of full-time education. Two covariates at the country level of analysis (level 2) were also included: old-age dependency and human development level. The 2008 index for old-age dependency was a country's ratio of older dependents (aged 64 and above) to its working-age population (aged 15-64) (World Bank, 2019). The 2008 Human Development Index (HDI) gave an indication of each country's development level regarding life expectancy, education and standards of living (United Nations Development Programme, 2019).

\section{Results}

Descriptive statistics are presented in Table 1. Correlation coefficients between the study variables are shown in the online supplementary material (Table S2 for level 1; Table S3 for level 2). The two forms of ageism correlate positively $(r=0.13)$. Furthermore, subtle and blatant ageism correlates with all predictors and mediators, apart from S-EN. Self-enhancement had either an insignificant effect on the ageism indicators or the effect was too small and was confounded empirically with other factors. The level- 2 covariate HDI was associated positively with EGAL and negatively with HRCHY, a result which corroborates other findings in the literature (Schwartz, 2006). As expected, EGAL and HRCHY correlated negatively.

Hierarchical regression analyses showed that the study covariates alone explained a modest proportion of variance due to level-1 differences (individual variation) in both subtle ageism, 0.9 per cent, and in blatant ageism, 0.3 per cent (see Table 2). Regarding the level-2 variance (country variation), the study covariates explained 8.8 per cent of subtle ageism and 31.1 per cent of blatant ageism. The inclusion of all study predictors and mediators improved the explained variance considerably. Regarding level-1 findings, all regression coefficients were in the predicted direction and the evidence was strong against chance results. All regression 
Table 1. Descriptive statistics: levels 1 and 2

\begin{tabular}{|c|c|c|}
\hline & ESS-4 & WVS-6 \\
\hline \multicolumn{3}{|l|}{ Level 1: } \\
\hline Gender (\% female) & 52.90 & 51.40 \\
\hline Age & $31.13(8.60)$ & $30.88(7.99)$ \\
\hline Years full-time education/Age when education was completed & $12.83(3.68)$ & $20.31(8.77)$ \\
\hline Value: S-TR & $4.81(0.72)$ & $4.50(1.18)$ \\
\hline Value: S-EN & $3.99(1.00)$ & $3.87(1.19)$ \\
\hline Threat: consumption & $5.09(2.71)$ & $1.99(0.70)$ \\
\hline Threat: succession & $7.16(2.26)$ & $2.56(0.89)$ \\
\hline Stereotype: warmth & $2.89(0.97)$ & $2.76(1.11)$ \\
\hline Stereotype: competence & $2.36(1.04)$ & $2.50(1.17)$ \\
\hline Ageism: subtle (reverse coded) & $7.45(1.88)$ & NA \\
\hline Ageism: blatant (reverse coded) & $4.93(2.76)$ & $6.06(2.72)$ \\
\hline N (listwise) & 23,216 & 41,563 \\
\hline \multicolumn{3}{|l|}{ Level 2: } \\
\hline Old-age dependency 2008/2010 & $22.69(4.40)$ & $13.17(7.33)$ \\
\hline HDI 2008/2010 & $0.85(0.06)$ & $0.75(0.11)$ \\
\hline EGAL & $4.76(0.29)$ & $4.64(0.25)$ \\
\hline HRCHY & $2.10(0.37)$ & $2.48(0.53)$ \\
\hline k (listwise) & 29 & 40 \\
\hline
\end{tabular}

Notes: Values are means and standard deviations. ESS-4: European Social Survey Round 4. WVS-6: World Value Survey Round 6. S-TR: self-transcendence. S-EN: self-enhancement. HDI: Human Development Index. EGAL: egalitarianism. HRCHY: hierarchy. NA: not applicable.

coefficients, meanwhile, were significant, apart from the effect of S-TR on blatant ageism. Only one level-2 regression coefficient was significant (also in the predicted direction), namely the effect of EGAL on blatant ageism.

As can be seen in Figure 2, the direct effects of S-TR were significant and in the expected direction. The direct effects of S-EN were likewise in the predicted direction, but only the association with subtle ageism was statistically significant. The effects were partially mediated by threat perception and stereotype content (see Table 3). Threat perception indicators mediated the effect of S-TR on subtle ageism and the effect of S-EN on both forms of ageism. Stereotype content likewise provided a unique explanation for the effect of value priorities on both, and all total indirect effects were positive and significant.

The effects of S-TR on both forms of ageism were partially explained by threat perception and stereotype content together acting as mediators (i.e. mediators in paralleled series). On the other hand, the effects of S-EN on subtle and blatant forms of ageism were not explained by threat perception and stereotype content together acting as mediators. 
Table 2. Multilevel regression analyses for the prediction of ageism in the population aged 45 and younger across countries

\begin{tabular}{|c|c|c|c|c|c|c|}
\hline & \multicolumn{4}{|c|}{ ESS-4 } & \multicolumn{2}{|c|}{ WVS-6 } \\
\hline & \multicolumn{2}{|c|}{ Subtle ageism } & \multicolumn{2}{|c|}{ Blatant ageism } & \multicolumn{2}{|c|}{ Blatant ageism } \\
\hline & Covariates & Full model & Covariates & Full model & Covariates & Full model \\
\hline \multicolumn{7}{|l|}{ Level 1: } \\
\hline Age & $\begin{array}{l}0.012^{\star \star} \\
(0.009,0.016)\end{array}$ & $\begin{array}{l}0.008^{\star \star}(0.00 \\
0.012)\end{array}$ & $\begin{array}{l}0.002(-0.002 \\
0.006)\end{array}$ & $\begin{array}{l}-0.004 \\
(-0.007,0)\end{array}$ & $\begin{array}{l}0.006^{\star *}(0.002 \\
0.010)\end{array}$ & $\begin{array}{l}0.007^{\star \star} \\
(0.002,0.012)\end{array}$ \\
\hline Female & $\begin{array}{l}0.225^{\star \star} \\
(0.166,0.283)\end{array}$ & $\begin{array}{l}0.172^{\star \star} \\
(0.113,0.230)\end{array}$ & $\begin{array}{l}-0.278^{\star \star} \\
(-0.343,-0.212)\end{array}$ & $\begin{array}{l}-0.300^{\star \star} \\
(-0.366 \\
-0.233)\end{array}$ & $\begin{array}{l}-0.096^{\star *}(-0.159 \\
-0.034)\end{array}$ & $\begin{array}{l}-0.096^{\star \star} \\
(-0.171 \\
-0.019)\end{array}$ \\
\hline $\begin{array}{l}\text { Years of full-time education/Age } \\
\text { when education completed }\end{array}$ & $\begin{array}{l}0.019^{\star \star} \\
(0.010,0.027)\end{array}$ & $\begin{array}{l}0.019^{\star \star} \\
(0.010,0.028)\end{array}$ & $\begin{array}{l}0.012^{\star}(0.002 \\
0.022)\end{array}$ & $\begin{array}{l}0.019 \star \star \\
(0.009,0.029)\end{array}$ & $\begin{array}{l}-0.002(-0.005 \\
0.001)\end{array}$ & $\begin{array}{l}-0.003 \\
(-0.007,0)\end{array}$ \\
\hline Value: S-EN & & $\begin{array}{l}-0.063^{\star \star} \\
(-0.096 \\
-0.029)\end{array}$ & & $\begin{array}{l}-0.023 \\
(-0.061 \\
0.015)\end{array}$ & & $\begin{array}{l}0.064^{\star \star} \\
(0.026,0.101)\end{array}$ \\
\hline Value: S-TR & & $\begin{array}{l}0.453^{\star \star} \\
(0.407,0.496)\end{array}$ & & $\begin{array}{l}0.147^{\star \star} \\
(0.097,0.197)\end{array}$ & & $\begin{array}{l}0.021(-0.007 \\
0.048)\end{array}$ \\
\hline Threat: consumption & & $\begin{array}{l}-0.057^{\star \star} \\
(-0.068 \\
-0.046)\end{array}$ & & $\begin{array}{l}-0.016^{\star} \\
(-0.029 \\
-0.003)\end{array}$ & & $\begin{array}{l}-0.129^{\star \star} \\
(-0.190 \\
-0.068)\end{array}$ \\
\hline Threat: succession & & $\begin{array}{l}-0.022^{\star \star} \\
(-0.036 \\
-0.009)\end{array}$ & & $\begin{array}{l}-0.148^{\star \star} \\
(-0.164 \\
-0.133)\end{array}$ & & $\begin{array}{l}0.012(-0.025, \\
0.048)\end{array}$ \\
\hline Stereotype: warmth & & $\begin{array}{l}0.432^{\star \star} \\
(0.398,0.466)\end{array}$ & & $\begin{array}{l}0.131^{\star \star} \\
(0.092,0.170)\end{array}$ & & $\begin{array}{l}0.161^{\star \star} \\
(0.112,0.200)\end{array}$ \\
\hline Stereotype: competence & & $\begin{array}{l}0.100^{\star \star} \\
(0.068,0.131)\end{array}$ & & $\begin{array}{l}0.360^{\star \star} \\
(0.323,0.397)\end{array}$ & & $\begin{array}{l}0.499^{\star \star} \\
(0.462,0.535)\end{array}$ \\
\hline
\end{tabular}




\begin{tabular}{|c|c|c|c|c|c|c|}
\hline$N$ & 26,344 & 24,138 & 25,224 & 23,349 & 44,926 & 28,909 \\
\hline$R^{2}(\%)$ & 0.9 & 11.9 & 0.3 & 5.4 & 0.1 & 6.4 \\
\hline \multicolumn{7}{|l|}{ Level 2: } \\
\hline Old-age dependency & $\begin{array}{l}0.010(-0.029 \\
0.049)\end{array}$ & $\begin{array}{l}0.011(-0.029 \\
0.053)\end{array}$ & $\begin{array}{l}-0.030(-0.102 \\
0.041)\end{array}$ & $\begin{array}{l}-0.025 \\
(-0.093 \\
0.042)\end{array}$ & $\begin{array}{l}-0.020(-0.063 \\
0.023)\end{array}$ & $\begin{array}{l}-0.015 \\
(-0.068 \\
0.039)\end{array}$ \\
\hline $\mathrm{HDI}$ & $\begin{array}{l}1.381(-1.659 \\
4.412)\end{array}$ & $\begin{array}{l}3.321(-0.867 \\
7.447)\end{array}$ & $\begin{array}{l}9.388^{*}(3.821, \\
14.936)\end{array}$ & $\begin{array}{l}5.068(-1.773, \\
11.839)\end{array}$ & $\begin{array}{l}-0.244(-3.109 \\
2.627)\end{array}$ & $\begin{array}{l}-0.444 \\
(-3.632 \\
2.757)\end{array}$ \\
\hline EGAL & & $\begin{array}{l}-0.613 \\
(-1.330 \\
0.095)\end{array}$ & & $\begin{array}{l}1.696^{\star \star} \\
(0.530,2.837)\end{array}$ & & $\begin{array}{l}1.220(-0.058, \\
2.519)\end{array}$ \\
\hline $\mathrm{HRCHY}$ & & $\begin{array}{l}-0.050 \\
(-0.661 \\
0.576)\end{array}$ & & $\begin{array}{l}0.322(-0.689, \\
1.348)\end{array}$ & & $\begin{array}{l}0.793^{\star} \\
1.410)\end{array}$ \\
\hline K & 29 & 29 & 29 & 29 & 57 & 40 \\
\hline$R^{2}(\%)$ & 8.8 & 22.6 & 31.1 & 49.3 & 5.1 & 25.4 \\
\hline ICC (\%) & 4.3 & & 9.4 & & 10.8 & \\
\hline
\end{tabular}

Notes: Values are regression coefficients and confidence intervals (CI). ESS-4: European Social Survey Round 4. WVS-6: World Value Survey Round 6. S-EN: self-enhancement. S-TR: self-transcendence. HDI: Human Development Index. EGAL: egalitarianism. HRCHY: hierarchy. ICC: intra-class correlation.

Significance levels: * $\alpha=95$ per cent $\mathrm{Cl},{ }^{* \star} \alpha=99$ per cent $\mathrm{Cl}$ (Bayesian bootstrapped). 

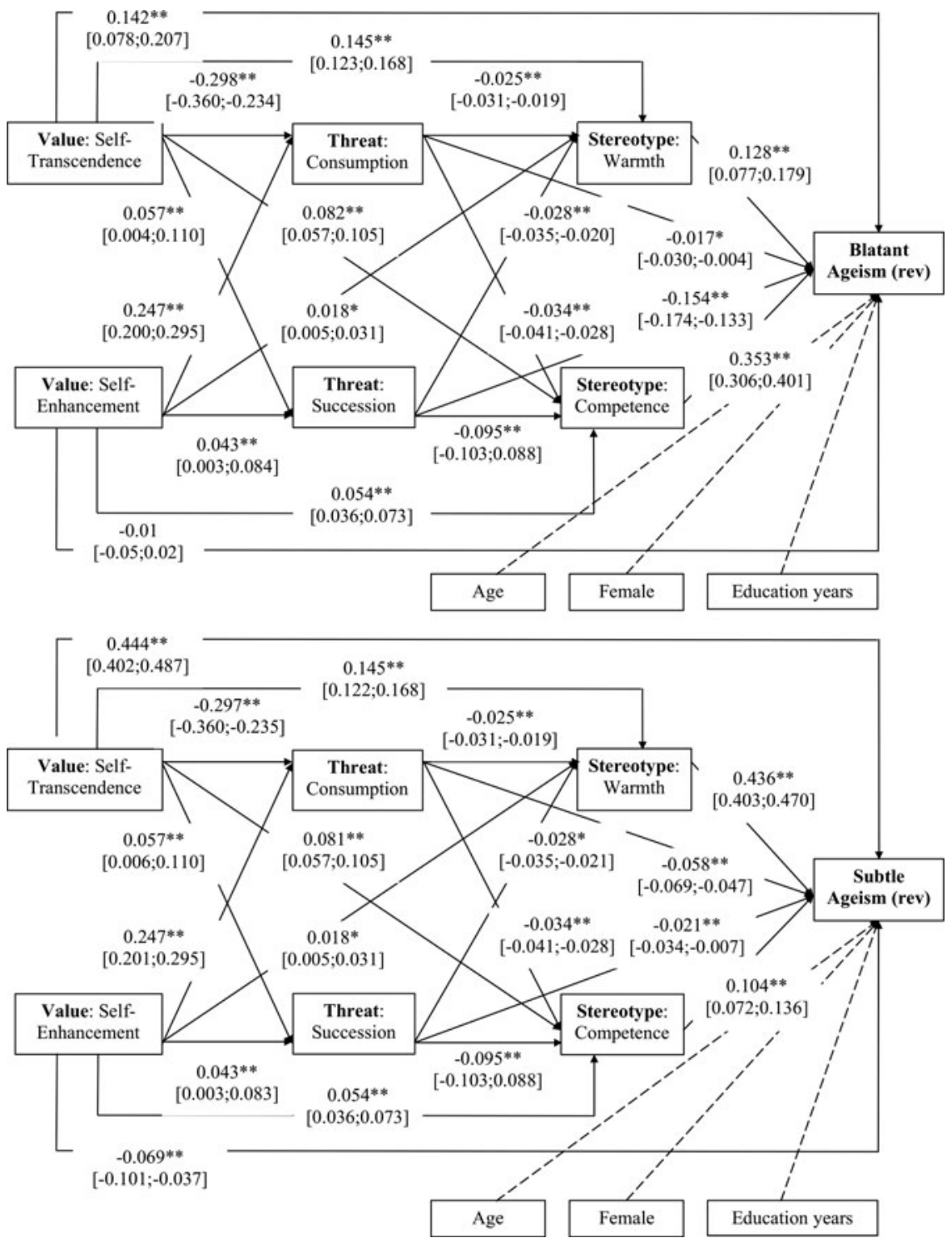

Figure 2. Direct effect in the mediation models estimated with European Social Survey data. Notes: Values are regression coefficients and confidence intervals $(\mathrm{Cl})$. rev: reverse coded. Significance levels: * $\alpha=95$ per cent $\mathrm{Cl},{ }^{\star \star} \alpha=99$ per cent $\mathrm{Cl}$ (Bayesian bootstrapped).

\section{Discussion}

Strong support was found for Hypotheses 1 and 2. The present results corroborate the existing literature, which explains ageism as a function of stereotypes and threat perception (North and Fiske, 2012, 2013; Voss et al., 2018). Moreover, these results also have the potential to advance the field of research on the context-dependency 
Table 3. Level-1 mediation analyses for the prediction of ageism in the population aged 45 and younger

\begin{tabular}{|c|c|c|c|c|c|c|c|c|c|c|}
\hline \multirow[b]{3}{*}{ Predictors } & & \multicolumn{6}{|c|}{ ESS-4 } & \multicolumn{3}{|c|}{ WVS-6 } \\
\hline & & \multicolumn{3}{|c|}{ Subtle ageism } & \multicolumn{3}{|c|}{ Blatant ageism } & \multicolumn{3}{|c|}{ Blatant ageism } \\
\hline & & $\begin{array}{l}\text { Specific } \\
\text { indirect }\end{array}$ & $\begin{array}{c}\text { Total } \\
\text { indirect }\end{array}$ & $\begin{array}{l}\text { Total } \\
\text { effect }\end{array}$ & $\begin{array}{l}\text { Specific } \\
\text { indirect }\end{array}$ & $\begin{array}{c}\text { Total } \\
\text { indirect }\end{array}$ & $\begin{array}{l}\text { Total } \\
\text { effect }\end{array}$ & $\begin{array}{l}\text { Specific } \\
\text { indirect }\end{array}$ & $\begin{array}{c}\text { Total } \\
\text { indirect }\end{array}$ & $\begin{array}{l}\text { Total } \\
\text { effect }\end{array}$ \\
\hline \multicolumn{11}{|c|}{$\mathrm{M}_{1}$ and $\mathrm{M}_{2}$ in parallel: } \\
\hline \multirow[t]{2}{*}{$X_{1}$} & $a_{1} b_{1}$ & $\begin{array}{l}0.017^{\star \star} \\
(0.013 \\
0.022)\end{array}$ & $\begin{array}{l}0.016^{\star \star} \\
(0.011 \\
0.022)\end{array}$ & $\begin{array}{l}0.460^{\star \star} \\
(0.417 \\
0.503)\end{array}$ & $\begin{array}{l}0.005^{\star} \\
(0.001 \\
0.009)\end{array}$ & $\begin{array}{l}-0.004 \\
(-0.011 \\
0.004)\end{array}$ & $\begin{array}{l}0.138^{\star \star} \\
(0.074 \\
0.204)\end{array}$ & $\begin{array}{l}0.005^{\star \star} \\
(0.003,0.008)\end{array}$ & $\begin{array}{l}0.005^{\star \star} \\
(0.003 \\
0.008)\end{array}$ & $\begin{array}{l}0.027^{\star} \\
(0.001, \\
0.053)\end{array}$ \\
\hline & $a_{1}^{\prime} b_{2}$ & $\begin{array}{l}0.006^{\star \star} \\
(0.002 \\
0.011)\end{array}$ & & & $\begin{array}{l}0.046^{\star \star} \\
(0.035 \\
0.058)\end{array}$ & & & $\begin{array}{l}0(-0.001 \\
0.001)\end{array}$ & & \\
\hline \multirow[t]{2}{*}{$x_{2}$} & $a_{2} b_{2}$ & $\begin{array}{l}-0.001 \\
(-0.002,0)\end{array}$ & $\begin{array}{l}-0.015^{\star \star} \\
(-0.020 \\
-0.011)\end{array}$ & $\begin{array}{l}-0.084^{\star \star} \\
(-0.116 \\
-0.052)\end{array}$ & $\begin{array}{l}-0.007^{\star} \\
(-0.011 \\
-0.002)\end{array}$ & $\begin{array}{l}-0.011^{\star \star} \\
(-0.019 \\
-0.003)\end{array}$ & $\begin{array}{l}-0.026 \\
(-0.063 \\
0.011)\end{array}$ & $\begin{array}{l}0(-0.001, \\
0.002)\end{array}$ & $\begin{array}{l}-0.007^{\star \star} \\
(-0.010 \\
-0.003)\end{array}$ & $\begin{array}{l}0.053^{\star \star} \\
(0.018 \\
0.087)\end{array}$ \\
\hline & $a_{2}^{\prime} b_{1}$ & $\begin{array}{l}-0.002^{\star} \\
(-0.004 \\
-0.001)\end{array}$ & & & $\begin{array}{l}-0.001 \\
(-0.002,0)\end{array}$ & & & $\begin{array}{l}-0.006^{\star \star} \\
(-0.010 \\
-0.003)\end{array}$ & & \\
\hline \multicolumn{11}{|c|}{$\mathrm{M}_{3}$ and $\mathrm{M}_{4}$ in parallel: } \\
\hline \multirow[t]{2}{*}{$X_{1}$} & $a_{1}^{\prime \prime \prime} b_{3}$ & $\begin{array}{l}0.063^{\star \star} \\
(0.052 \\
0.074)\end{array}$ & $\begin{array}{l}0.072^{\star \star} \\
(0.060 \\
0.083)\end{array}$ & $\begin{array}{l}0.515^{\star \star} \\
(0.472 \\
0.559)\end{array}$ & $\begin{array}{l}0.019^{\star \star} \\
(0.011 \\
0.027)\end{array}$ & $\begin{array}{l}0.047^{\star \star} \\
(0.036 \\
0.059)\end{array}$ & $\begin{array}{l}0.190^{\star \star} \\
(0.124 \\
0.255)\end{array}$ & $\begin{array}{l}0.008^{\star \star} \\
(0.005,0.011)\end{array}$ & $\begin{array}{l}0.022^{\star \star} \\
(0.014 \\
0.031)\end{array}$ & $\begin{array}{l}0.044^{\star \star} \\
(0.008 \\
0.080)\end{array}$ \\
\hline & $a_{1} b_{4}$ & $\begin{array}{l}0.008^{\star \star} \\
(0.005 \\
0.012)\end{array}$ & & & $\begin{array}{l}0.029 * \star \\
(0.020 \\
0.039)\end{array}$ & & & $\begin{array}{l}0.015^{\star \star} \\
(0.007,0.023)\end{array}$ & & \\
\hline \multirow[t]{2}{*}{$x_{2}$} & $a_{2}^{\prime \prime \prime} b_{4}$ & $\begin{array}{l}0.006^{\star \star} \\
(0.003 \\
0.008)\end{array}$ & $\begin{array}{l}0.013^{\star \star} \\
(0.005 \\
0.021)\end{array}$ & $\begin{array}{l}-0.056^{\star \star} \\
(-0.088 \\
-0.023)\end{array}$ & $\begin{array}{l}0.019^{\star \star} \\
(0.012 \\
0.027)\end{array}$ & $\begin{array}{l}0.021^{\star \star} \\
(0.014 \\
0.029)\end{array}$ & $\begin{array}{l}0.006 \\
(-0.031 \\
0.044)\end{array}$ & $\begin{array}{l}0.017^{\star \star} \\
(0.009,0.025)\end{array}$ & $\begin{array}{l}0.018^{\star \star} \\
(0.010 \\
0.026)\end{array}$ & $\begin{array}{l}0.077^{\star \star} \\
(0.041 \\
0.113)\end{array}$ \\
\hline & $a_{2} b_{3}$ & $\begin{array}{l}0.008^{\star} \\
(0.002 \\
0.013)\end{array}$ & & & $\begin{array}{l}0.002^{\star} \\
(0.001 \\
0.004)\end{array}$ & & & $\begin{array}{l}0.001 \\
(-0.001 \\
0.003)\end{array}$ & & \\
\hline
\end{tabular}


Table 3. (Continued.)

\begin{tabular}{|c|c|c|c|c|c|c|c|c|c|c|}
\hline \multirow[t]{3}{*}{ Predictors } & & \multicolumn{6}{|c|}{ ESS-4 } & \multicolumn{3}{|c|}{ WVS-6 } \\
\hline & & \multicolumn{3}{|c|}{ Subtle ageism } & \multicolumn{3}{|c|}{ Blatant ageism } & \multicolumn{3}{|c|}{ Blatant ageism } \\
\hline & & $\begin{array}{l}\text { Specific } \\
\text { indirect }\end{array}$ & $\begin{array}{c}\text { Total } \\
\text { indirect }\end{array}$ & $\begin{array}{l}\text { Total } \\
\text { effect }\end{array}$ & $\begin{array}{l}\text { Specific } \\
\text { indirect }\end{array}$ & $\begin{array}{c}\text { Total } \\
\text { indirect }\end{array}$ & $\begin{array}{l}\text { Total } \\
\text { effect }\end{array}$ & $\begin{array}{l}\text { Specific } \\
\text { indirect }\end{array}$ & $\begin{array}{c}\text { Total } \\
\text { indirect }\end{array}$ & $\begin{array}{l}\text { Total } \\
\text { effect }\end{array}$ \\
\hline \multicolumn{11}{|c|}{$M_{1}-M_{4}$ in paralleled series: } \\
\hline \multirow[t]{4}{*}{$\mathrm{X}_{1}$} & $a_{1} d_{1} b_{3}$ & $\begin{array}{l}0.003^{\star \star} \\
(0.002 \\
0.004)\end{array}$ & $\begin{array}{l}0.091^{\star \star} \\
(0.078 \\
0.104)\end{array}$ & $\begin{array}{l}0.535^{\star \star} \\
(0.492 \\
0.579)\end{array}$ & $\begin{array}{l}0.001^{\star \star} \\
(0.001 \\
0.002)\end{array}$ & $\begin{array}{l}0.046^{\star \star} \\
(0.030 \\
0.062)\end{array}$ & $\begin{array}{l}0.188^{\star \star} \\
(0.123 \\
0.254)\end{array}$ & $\begin{array}{l}0.001^{\star \star} \\
(0.001,0.001)\end{array}$ & $\begin{array}{l}0.029^{\star \star} \\
(0.021 \\
0.038)\end{array}$ & $\begin{array}{l}0.051^{\star} \\
(0.015 \\
0.086)\end{array}$ \\
\hline & $a_{1} d_{1}^{\prime} b_{4}$ & $\begin{array}{l}0.001^{\star \star} \\
(0.001 \\
0.002)\end{array}$ & & & $\begin{array}{l}0.004^{\star \star} \\
(0.003 \\
0.005)\end{array}$ & & & $\begin{array}{l}0.001^{\star \star} \\
(0.001,0.002)\end{array}$ & & \\
\hline & $a_{1}^{\prime} d_{2}^{\prime} b_{3}$ & $\begin{array}{l}-0.001 \\
(-0.001,0)\end{array}$ & & & $0(0,0)$ & & & $0(0,0)$ & & \\
\hline & $a_{1}^{\prime} d_{2} b_{4}$ & $\begin{array}{l}-0.001 \\
(-0.001,0)\end{array}$ & & & $\begin{array}{l}-0.002^{\star} \\
(-0.003 \\
-0.001)\end{array}$ & & & $0(0,0)$ & & \\
\hline \multirow[t]{4}{*}{$x_{2}$} & $a_{2} d_{2} b_{4}$ & $0(-0.001,0)$ & $\begin{array}{l}-0.006 \\
(-0.013 \\
0.001)\end{array}$ & $\begin{array}{l}-0.075^{\star \star} \\
(-0.108 \\
-0.042)\end{array}$ & $\begin{array}{l}-0.001 \\
(-0.003,0)\end{array}$ & $\begin{array}{l}0.006 \\
(-0.003 \\
0.014)\end{array}$ & $\begin{array}{l}-0.010 \\
(-0.047 \\
0.028)\end{array}$ & $0(0,0)$ & $\begin{array}{l}0.010^{\star \star} \\
(0.001 \\
0.019)\end{array}$ & $\begin{array}{l}0.069^{\star \star} \\
(0.033 \\
0.106)\end{array}$ \\
\hline & $a_{2} d_{2}^{\prime} b_{3}$ & $\begin{array}{l}-0.001 \\
(-0.001,0)\end{array}$ & & & $0(0,0)$ & & & $0(0,0)$ & & \\
\hline & $a_{2}^{\prime} d_{1} b_{3}$ & $\begin{array}{l}-0.003^{\star \star} \\
(-0.004 \\
-0.002)\end{array}$ & & & $\begin{array}{l}-0.001^{\star} \\
(-0.001 \\
-0.001)\end{array}$ & & & $\begin{array}{l}-0.001^{\star \star} \\
(-0.001 \\
-0.001)\end{array}$ & & \\
\hline & $a_{2}^{\prime} d_{1}^{\prime} b_{4}$ & $\begin{array}{l}-0.001 \\
(-0.001,0)\end{array}$ & & & $\begin{array}{l}-0.002^{\star \star} \\
(-0.003 \\
-0.002)\end{array}$ & & & $0(0,0)$ & & \\
\hline
\end{tabular}


of ageism. We know that ageism is present in varying forms across such domains of life as the job market or within multigenerational families (Marques et al., 2020). We also know that people can stereotype senior citizens in different ways depending on the context (Kornadt and Rothermund, 2011). The present study approached the question of ageism from an intergenerational perspective (North and Fiske, 2013) and found that reactions due to competition over resources (threat in the consumption sector and stereotypical beliefs about degree of warmth) were more informative for younger people's overall prejudice against older people. Meanwhile, reactions due to position in society (threat to succession and stereotypical beliefs regarding competence) were found to be more relevant for younger people's discrimination towards older people. For younger people, it appears, some domains are more important for the subtler forms of ageism and other domains for the more blatant forms.

Support was found also for Hypothesis 3. S-TR predicted lower levels of subtle and blatant forms of ageism. S-EN, on the other hand, predicted only higher levels of subtle ageism. These results provide initial evidence that value preferences of younger people may contribute motivational forces for the suppression and justification of ageism. Notwithstanding, the findings specify the effects which are due to value preferences alone while other influencing factors are kept constant. This is an incomplete picture of the roles value systems might have on ageism since both the existing literature and the results discussed above show that threat perception as well as stereotypical beliefs play a significant role.

Support for Hypothesis 4 was partial. It is noteworthy that in countries with higher levels of EGAL (e.g. Belgium, Portugal, Spain) only blatant forms of ageism had lower levels, whereas with subtle forms of ageism there was no association. It is unclear what caused this, but one possibility is that the context-dependency argument which was mentioned above may have been operating also at the cultural level. Schwartz (2006) argued that egalitarian cultures prioritise values of equality, social justice, responsibility, help and honesty, which fits well with the idea that blatant forms of ageism are, or must be, suppressed. In stronger egalitarian countries, there are stronger norms towards the wellbeing of the collective than in the weaker egalitarian countries. Unlike discrimination against older people in the work sector, overall prejudice against older people does not carry context-relevant meaning. As a consequence, overall prejudice seems to be an intimate form of ageism which may or may not be expressed as such in public, where norms enforcing the wellbeing of others, including older people, operate overtly. Future research examining the effects of norm strength (Gelfand, 2012) on the inconsistency between implicit and explicit forms of ageism (Levy and Banaji, 2002; also see Vauclair et al., 2017) across egalitarian cultures might prove useful in settling this debate.

The main contributions of this study are the findings of the mediation analyses. As was argued above, the ageism we observe in society and in research might be misleading because (younger) people are able to manage and scrutinise their genuine ageism to an extent which depends on their inner and external motivations for suppressing and justifying it (Crandall and Eshleman, 2003). The results indicate that despite the negative effects of threat perception and stereotypes, the ageism a person expresses, be it subtle or blatant, is deeply and positively influenced by that person's self-transcendence values (Hypothesis 5). This finding supports the 
idea that internal motivational forces may dictate the expression of ageism in ways which are in line with one's personal values of suppressing thought or action which might harm the wellbeing of others.

Interestingly, however, the predicted justification effects of S-EN were not significant (Hypothesis 6), a finding which requires a closer look. One's personal values of advancing one's own position and success may justify higher threat perceptions and may thus develop into forms of subtle and blatant ageism which are more negative but fail to justify any genuine negative stereotypes. Quite the opposite: S-EN, it seems, provides motivational force for the justification of more positive stereotypes and thus evolves into forms of subtle and blatant ageism which are more positive. This has three possible explanations: (a) the operationalisation of stereotypes was inadequate, (b) other values play the said role, or (c) these values do not release ageism across European countries but might do so across other, non-European countries.

The first explanation is that S-EN failed to justify negative stereotypes because stereotypes in the ESS were measured with positively worded items. Crandall and Eshleman (2003) argued that only negative forms of genuine prejudice are subjected to motivational forces of suppression and justification. The positive forms, they wrote, are expressed as such without being altered by said processes. The participants in the ESS had to indicate how much (not at all likely to very much likely) they believed people over 70 were seen in their countries as being friendly and competent. The existing literature has generally interpreted answers on the lower ends of the scale (e.g. not at all likely to be friendly) as negative stereotypes towards senior citizens (e.g. Cuddy et al., 2005). Yet this is not necessarily the case. Bruckmüller and Abele (2013) showed by means of multi-dimensional scaling that negatively worded items measuring warmth and competence (e.g. unapproachable and lazy) are orthogonal to positively worded ones. The present operationalisation might thus have measured in actuality only whether a participant did not agree with the description that older people are friendly and competent but not whether the participant believed older people to be unfriendly and incompetent. Relatedly, we should be aware that stereotypes were operationalised as meta-beliefs rather than as subjective beliefs of the individual participants (Yzerbyt and Demoulin, 2012). This approach may not capture the true subjective beliefs held by (younger) people which are subjected to the justification motivational forces.

The second explanation is that values other than those of S-EN may provide motivational strength towards justifying ageism. Contrary to the expectation that values with opposing motivational content serve as suppressors and justifiers, respectively, of ageism, in practice it may be that values with neighbouring motivational content do. The alternative candidate is values of conservation, which emphasise stability, preservation of the past and resistance to change (Schwartz, 2012). Ageism against older people is structural; it has been passed on from generation to generation, and it may even have become more negative along the way (e.g. $\mathrm{Ng}$ et al., 2015). This may mean that individuals with a strong orientation towards values of conservation may have more difficulty thinking and acting otherwise towards older people in contexts which seek to challenge the existing status quo.

An additional possible explanation is that there is something unique to the European countries which has led to the non-result. Despite some heterogeneity 
in their economies, cultures and other factors, countries in the ESS-4 dataset appear very similar to each other in comparison to countries from other continents (Schwartz, 2006). Countries from the European Union, for instance, which represent the clear majority in that dataset, have a common legal framework for combating ageism (Georgantzi, 2018). This may provide similar external motivations which, in time, may be internalised by younger members of these societies and serve to suppress only their ageism. When other countries are included, their internal and external motivations for combating ageism might differ or might act in ways which diverge from the patterns prevailing in Europe. Studies which have compared collectivistic East Asian cultures against individualistic Western cultures, for example, have found that countries like Taiwan are more ageist than countries like England (North and Fiske, 2015; Vauclair et al., 2017), a finding which disconfirms the lay theory that Asian cultures are less ageist than Western cultures.

\section{Study 2}

It is still unclear for now whether, and to what extent, the findings in Study 1 are specific to the cluster represented in the ESS dataset or whether they are transferable to other contexts, as well. A confirmation of the previous findings in other contexts will contribute additional evidence about the justification-suppression qualities (or lack thereof) of value systems. On the other hand, however, a disconfirmation may unravel unique, culture-related insights.

Study 2 sought to examine the present hypotheses using the WVS-6 dataset, which contains information from 60 countries from six continents (Algeria, Argentina, Armenia, Australia, Azerbaijan, Bahrain, Belarus, Brazil, Chile, China, Colombia, Cyprus, Ecuador, Egypt, Estonia, Georgia, Germany, Ghana, Hong Kong, India, Iraq, Japan, Jordan, Kazakhstan, Kuwait, Kyrgyzstan, Lebanon, Libya, Malaysia, Mexico, Morocco, The Netherlands, New Zealand, Nigeria, Pakistan, Palestine, Peru, Philippines, Poland, Qatar, Romania, Russia, Rwanda, Singapore, Slovenia, South Africa, South Korea, Spain, Sweden, Taiwan, Thailand, Trinidad and Tobago, Tunisia, Turkey, Ukraine, USA, Uruguay, Uzbekistan, Yemen, Zimbabwe) and comprises a total of $\mathrm{N}=90,350$ participating individuals (mean age $=42,05, \mathrm{SD}=16.48$, range $=16-99$ ). The dataset encapsulates a set of countries which are highly heterogeneous in terms of culture, religion, economics and politics (Inglehart et al., 2014).

The existing literature has addressed ageism-related questions very little using the dataset. One exception is a study by Peterson and Ralston (2017), who showed that in Asian, Middle Eastern and sub-Saharan African countries people hold more negative views towards senior citizens than people in Western countries do. Another exception is a study by Zhang et al. (2016), who examined, across countries, whether personal and cultural values predicted stereotypes towards older people.

\section{Method}

Data and analytical strategy

Only study participants aged 45 and younger were selected $(\mathrm{N}=54,940$; mean age $=30.88, \mathrm{SD}=7.99$ ). Group-mean standardisation was applied for level-1 variables; 
grand-mean standardisation was applied for level-2 variables. Data were missing at both levels of analysis. At level 2, there was no available information for old-age dependency for Taiwan and Palestine (nor was an HDI score available for Palestine). No scores on EGAL and HRCHY were available for Algeria, Armenia, Azerbaijan, Bahrain, Belarus, Ecuador, Iraq, Kazakhstan, Kyrgyzstan, Kuwait, Lebanon, Morocco, Palestine, Qatar, Rwanda, Tunisia, Uruguay and Uzbekistan. Missing data were pairwise deleted (see Study 1). The sizes of the valid datasets used in each model estimation are given in the respective table of results (see Results). The dataset contains information only on blatant ageism; of the total variance, 10.8 per cent was due to country differences. The analytical strategy and estimated models were identical to those in Study 1.

\section{Measurement}

Unless otherwise specified, the measures were identical to those in Study 1.

Ageism. The blatant form of ageism was measured using the item $(1=$ completely unacceptable, $10=$ completely acceptable): 'Please tell me how acceptable or unacceptable you think most people in [e.g. Armenia] would find it if a suitably qualified 70-year-old were appointed as their boss?'

Value systems. S-EN and S-TR were measured using a short version of the PVQ instrument (Schwartz, 2003) in which each of the ten basic human values were assessed with single items. One item, for example, is 'It is important to this person to be rich; to have a lot of money and expensive things.' The scale measurement was identical to the one employed in Study $1(1=$ very much like me, $6=$ not at all like me). Two items made up SE: being rich and being successful (item correlation, $r=$ 0.29). Two items made up ST: care for the environment and helping other people (item correlation, $r=0.43$ ). The computational procedure for S-EN and S-TR was identical to the one in Study 1.

Threat perception. Threat perception was assessed concerning the consumption and the succession potential of older people (also see North and Fiske, 2013) by asking study participants whether they agreed with specific statements $(1=$ strongly agree, $4=$ strongly disagree). Threat perception regarding consumption (interchangeably, threat perception in the resource redistribution sector) was measured with two items (item correlation, $r=0.35$ ): 'Older people are a burden on society' and 'Older people get more than their fair share from the government.' The average of these items served as the index of threat perception in the consumption sector. Threat perception regarding succession (interchangeably, threat perception in the political sector) was measured with the item: 'Old people have too much political influence.'

The study covariates were identical with the ones used in Study 1, apart from two discrepancies: education level (a level-1 covariate) was assessed using the selfreported age at the time full-time education was completed, and the 2010 scores of the respective country indices were used for this (level-2 covariates). 


\section{Results}

Descriptive statistics are given in Table 1. Correlation coefficients are shown in the online supplementary material (Table S2 for level 1; Table S3 for level 2). All level-1 factors correlate positively with lower levels of blatant ageism, apart from threat perception concerning consumption, which had no association. Excepting the correlations with S-EN and threat perception in the succession domain, the signs of the regression coefficients were as predicted. EGAL and HRCHY correlated negatively, as expected.

Hierarchical regressions replicated several findings from Study 1 (see Table 2). The study covariates alone explained a modest proportion of variance at both levels of analysis: 0.1 per cent at level 1 and 5.1 per cent at level 2. As in Study 1, the inclusion of all predictors improved the explained variance considerably. Regarding level-1 predictors, only the effect of S-EN was significant. The sign of the regression coefficient, however, was - contrary to expectations - positive. The effect of threat perception in the resource redistribution domain was significant and negative; the effect of threat perception in the political sector was not significant. The effect of stereotype content was significant and had the predicted sign for warmth and competence indicators. Regarding level-2 factors, the effect of HRCHY was significant and - contrary to predictions - positive.

The mediation analysis partially replicated the findings of Study 1 (see Figure 3; Table 3). Together, threat perception indicators explained the effects of S-TR and of S-EN on blatant ageism. Whereas the indirect effect of S-TR was positive, the indirect effect of S-EN was negative. The effects of S-TR and of S-EN were likewise explained by stereotype indicators and their total indirect effects were positive, as in Study 1. All specific indirect effects were also positive and significant apart from the effect of S-EN caused by warmth, which was not significant.

Considering the mediating influence of threat perception and stereotype content together, the findings matched those of Study 1 . The total indirect effect of S-TR via the mediators was positive and significant. However, the total indirect effect of S-EN on blatant ageism was also positive and significant, which contradicted expectations.

\section{Discussion}

Support was found for Hypotheses 1 and 2, excepting the effects of threat in the succession sector. Perceived threat in terms of older people having too much political influence did not transfer into discrimination against them in the job market. This is plausible because it is not the perceived threat regarding succession in general which determines discrimination against older people. What determines it is the perceived threat in specific contexts of succession, which is associated with context-specific discrimination. As in Study 1, ageism seems context-dependent.

Partial support was found for Hypothesis 3 and strong support for Hypothesis 5, which thus provides strong overall evidence for the role of S-TR as a motivational force towards the suppression of ageism. The findings also add to those in Study 1 regarding the role of S-EN in justifying the more positive stereotypes against older people. Yet, contrary to the previous study, an unexpected finding concerns the total indirect effect of S-EN (Hypothesis 6). Despite the combined negative effects 
of threat perception and stereotypes, blatant ageism amongst younger people from a mostly non-European (i.e. non-Western) cluster of countries was suppressed by both self-transcendence and self-enhancement. The influence of the former was slightly stronger than of the latter. This suggests that there might be two ways towards the suppression of blatant ageism - a specific Western one which draws on values of universalism and benevolence, and a specific, non-Western one which involves the values of universalism and benevolence and of achievement and power. These results capture the duality existing in hierarchical-collectivistic cultures where personal success, or self-enhancement, is woven with maintaining face, or self-transcendence (Heine and Hamamura, 2007).

Contrary to the prediction of Hypothesis 4, ageism was less blatant in countries with higher hierarchy levels. This finding corroborates the results obtained by Löckenhoff et al. (2009), who found more favourable views on ageing in hierarchical cultures, especially concerning perceived respect and family authority. This adds intriguing new insights to those of Study 1. For instance, Delhey et al. (2018) argued that the Western approach to achieving societal progress and modernisation - through less inequality, more economic development or greater secularisation - is just one way out of many and must not be taken as the standard in non-Western, countries. In Asian countries, they found that societal modernisation means economic development but also a certain level of hierarchy. Asian cultures are hierarchical-collectivistic, which implies that Confucian teachings are institutionalised and embedded in the social fabric. This entails enforcing, for example, respect for older people amongst the younger population (Schwartz, 2006). Indeed, correlations in the ESS-4 (in which Western countries have a clear majority) and WVS- 6 datasets (with a majority of non-Western countries) between modernisation levels and EGAL ( $r=0.63$ versus $r=0.27)$ and HRCHY $(r=-0.64$ versus $r=-0.23$ ) encourage the interpretation that blatant ageism is less problematic in such hierarchical countries due to their specific approach to societal modernisation. Egalitarianism provides external motivations for the suppression of ageism in Western countries. Outside the Western world, however, as in Asian countries, hierarchy appears to be an external source of motivation in the suppression of ageism (also see Vauclair et al., 2017).

\section{General discussion}

The present results highlight the importance of being holistic in the study of ageism. Independently, threat perception and stereotypes seem to impact ageism differently. Yet ageism is complex and involves affective and behavioural responses which are in turn determined by cognitive reactions. We must be cautious because the internal motivations and subjective perceptions involved in the reactions of younger individuals towards older individuals make such reactions complex. Something we need to consider equally important are the ways in which the cultural environment in which people reside shapes all such reactions. The present article integrates the core findings of existing approaches to explaining ageism and suggests that value systems represent motivational forces which can suppress, and to some degree justify, the expression of ageism in (younger) individuals (Crandall and Eshleman, 2003). 


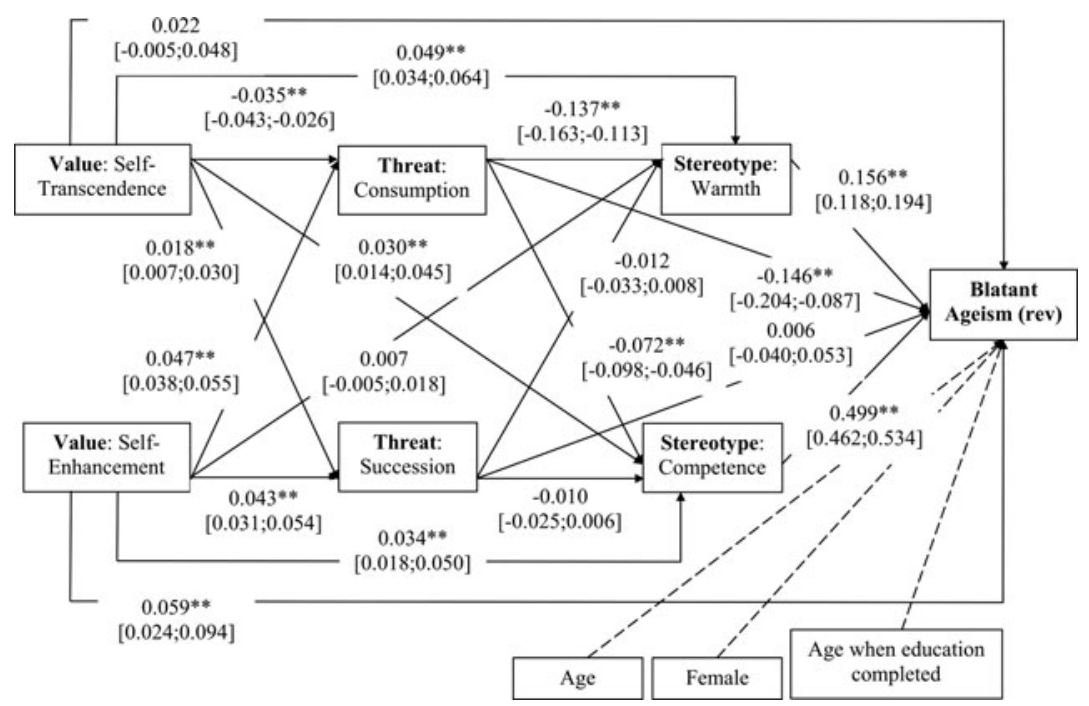

Figure 3. Direct effects in the mediation model estimated with World Value Survey data. Notes: Values are regression coefficients and confidence intervals $(\mathrm{Cl})$. rev: reverse coded. Significance level: ${ }^{\star \star} \alpha=95$ per cent $\mathrm{Cl}$ (Bayesian bootstrapped).

It was argued above that values are standards which dictate the way people interact with the social environment (Schwartz, 2012) and therefore precede any perceptions of threat or stereotypical beliefs about older people. Evidence replicated across egalitarian Western and hierarchical non-Western countries and across subtle and blatant forms of ageism shows that self-transcendence values are an internal motivational force for the suppression of ageism amongst younger people. A high preference for self-transcendence values can undermine the negative effects of threat perception and of stereotypical beliefs resulting therefore in a form of expressed ageism which is less negative. These results corroborate the existing findings regarding racial prejudice (Feather and McKee, 2011; Falanga et al., 2015; Florez et al., 2019). Contrary to expectations, self-enhancement can also suppress negative forms of ageism, although the effect appears to be specific to young individual members of hierarchical non-Western cultures.

Collectively, the existing studies have failed to provide conclusive evidence regarding the motivational force of value systems towards justifying negative forms of ageism. One explanation for this is that there was not much to justify in the present datasets. Self-enhancement values can provide, at the individual level, the right motivation towards leading from higher threat perception to forms of subtle and blatant ageism which are more negative - and yet that is seemingly not the case with respect to stereotypes. The measurement of stereotypes in the two reported studies was worded positively and operationalised as meta-beliefs which raises questions of whether younger individual members across societies indeed expressed the subjective and genuine negative beliefs they may have associated with senior citizens (Vauclair et al., 2017). 
The second explanation is that other values might be better candidates. Conservative values, it was suggested, are good alternatives at the individual level. The possibility has precedents in the work of Zhang et al. (2016), yet there is one distinct difference between that approach and the one proposed here. Zhang et al. (2016) compiled an index from self-transcendence and conservative values which probed communal values. The index, the authors found, was positively associated with stereotypes towards older people. Their approach was reductionist, however, as it disregarded theoretical considerations (Schwartz, 2012; also see Introduction). It is unclear what the separate effects of self-transcendence and conservation were, given that, as the present research shows, the former can provide motivational force towards suppressing ageism. The latter, on the other hand, might provide motivational strength towards justifying ageism. These forces can interact between each other with the suppression force emerging as more potent (Crandall and Eshleman, 2003) in contexts with stronger anti-ageism norms, such as in the European context (Georgantzi, 2018).

Values of mastery might be alternatives at the cultural level. Mastery emphasises ambition, success and competence in order to master, direct and change the natural and social environment to fulfil personal or group goals (Schwartz, 2006). This seems more relevant for younger members of rapidly ageing societies where greater proportions of older people live and allegedly are competing with them over resources (North and Fiske, 2012, 2013). After all, ageism against older people is a way to justify, internally and externally, action and thought towards achieving mastery over members of that age group in terms of access to resources available in society and in terms of succession, whether financial or political. The right external motivational force for justifying ageism, it seems, is not the 'it is how it is' approach to dealing with the societal issue of population ageing, but it may possibly be the 'take what is yours' approach.

Interestingly, the studies hint at evidence that suppression-justification processes in dealing with ageism might depend on contexts of interaction. For instance, as was observed earlier, the domain of consumption elicits more negativity in terms of subtle ageism than in terms of blatant ageism. If we are to follow Wang's (2003) propositions regarding racism, then it is within the realm of possibilities that ageism is situational. Can we be entirely sure that a person who discriminates on the basis of race in one set of circumstance, Wang (2003) wrote, would do so in another circumstance or in the same way? Like racism, ageism is not dispositional, as in personality or value preferences. Can we be entirely sure that a younger person who discriminates against an older person in the context of work would do so also in the context of electing a leader?

\section{Combating ageism via appropriate value change}

The genuine (primal, unaltered, scrutinised) form of ageism which a person holds may not always be expressed as such in society. This possibility makes it difficult for researchers and practitioners to find appropriate methods in combating ageism. Although there are some successful interventions which rely on, for example, the contact hypothesis (Requena et al., 2018), such approaches might curb the expression of ageism and not the genuine ageism per se. Fostering 
contact with senior citizens can alleviate threat perceptions and improve the stereotypes of older people held by younger individuals, but it is nonetheless possible that these changes are temporary (also see de Paula Couto and Wentura, 2017).

A strategy which may prove more fruitful in the long run, not only concerning ageism, but regarding 'isms' in general (e.g. racism and sexism), would be to target corresponding change in value systems. Contrary to lay beliefs, values are not stable across the lifespan; they are adaptable and will match the life circumstances of the person (Bardi and Goodwin, 2011; Bardi et al., 2014). Achieving changes in values requires effort and time, but it is in no way different than aiming to change attitudes and behaviour in ageist individuals. According to present findings, two value typologies are appropriate candidates for combating ageism: self-transcendence, which is a motivational force for the suppression of both blatant and subtle forms of ageism across countries, and self-enhancement, which is a motivational force for the suppression of ageism which is probably specific to hierarchical non-Western societies.

Genuine ageism, or at least its expression in society, may be curbed by, for instance, strategies aimed at facilitating a long-term increase in people's preference for self-transcending values (universalism and benevolence). Bardi and Goodwin (2011) have argued that changes in long-term values are possible when any initial and automatic value modification is reinforced constantly through concerted thinking. Existing interventions already achieve the initial steps whereby, for example, young adults learn to accept and appreciate the experiences, life histories and abilities of older people (Drury et al., 2016; Requena et al., 2018). Nonetheless, a crucial subsequent step must also be implemented for such strategies to be truly successful in the long run. They need to ensure that the targeted audience also 'does its part' after the completion of the intervention. This may be achieved as simply as by periodically following up the programme with content which challenges negative views on ageing via newsletters, emailing list or phone calls, to name a few dissemination channels. According to Bardi and Goodwin (2011), if the original value is challenged for a sufficiently long period, long-term changes in values will follow. A question for future research is exactly how long the period should be for effecting lasting changes in values in order to mitigate ageism.

Nonetheless, there is good news for opponents of ageism: younger people are more susceptible to changes in values than are older people (Bardi and Goodwin, 2011). Although ageism against older people is very common amongst the younger generations (Martens et al., 2005; North and Fiske, 2013, 2017), strategic interventions which encourage their preference for self-transcendence values might alleviate the urgency of the issue.

Cultural aspects must be factored into interventions dealing with changes in values which may lead to a reduction in ageism amongst younger people (Bardi and Goodwin, 2011). According to the results presented here, targeting self-transcendence values alone might be a viable solution in egalitarian Western societies, but may be an incomplete one in hierarchical non-Western societies where self-enhancement values may also play a part. 


\section{Limitations and future research direction}

All study results are correlational and should be interpreted accordingly. Ageism is a sensitive issue in society and therefore any correlational evidence concerning its explanation must be backed up with causal evidence. Temporal causality by means of longitudinal research can prove useful in this endeavour. Existing longitudinal datasets, such as the Survey of Health, Ageing and Retirement in Europe (SHARE; Börsch-Supan et al., 2013), or country-specific ones like the German Socio-Economic Panel (GSOEP; Kroh et al., 2018), contain repeatedly assessed information regarding ageism-related experiences and factors which probe value systems. An analysis of these datasets might identify causal confirmation for the present correlational findings.

It has been argued here that (younger) people can suppress (manipulate, alter) their genuine ageism before expression due to internal and external motivational forces stemming from value systems. In this study, however, genuine ageism was considered latent in the minds of people and only its expression was traced back to the standards of living of a person - their value system. At this stage, it remains a task for future research to determine a person's genuine ageism and how value systems might suppress or justify it, thereby leading to the expressed forms of ageism. Unobtrusive methodologies, such as the Implicit Association Test (Chopik and Giasson, 2017), can be used in future research to examine associations between raw forms of ageism and forms of ageism which can be manipulated before expression.

\section{Conclusion}

This study provides the first evidence that value systems are sources of internal and external motivation in the suppression of ageism amongst young adults. Drawing on multilevel analyses of two multinational datasets, the results show that self-transcendence values can suppress the negative effects of threat perception and of negative stereotypes, resulting in less negative expressions of both subtle and blatant forms of ageism. Whereas this finding seems universal across societies, it is also possible that a combination of self-enhancement and self-transcendence values operate in hierarchical non-Western societies which aid in the suppression of ageism.

Supplementary material. The supplementary material for this article can be found at https://doi.org/10. 1017/S0144686X20001257.

Data. Data and material associated with the article have been made available via https://osf.io/4sfnb/

Financial support. The author received no funding for the preparation of this article.

Ethical standards. No ethical approval was needed.

\section{References}

Abrams D, Russel P, Vauclair CM and Swift H (2011) Ageism in Europe. Findings from the European Social Survey. London: Age UK.

Ayalon L and Tesch-Römer C (2018) Contemporary Perspectives on Ageism. Springer Open. https://doi. org/10.1007/978-3-319-73820-8. 
Bahns AJ (2015) Threat as justification of prejudice. Group Processes \& Intergroup Relations 20, 52-74.

Bardi A and Goodwin R (2011) The dual route to value change: individual and cultural moderators. Journal of Cross-cultural Psychology 42, 271-287.

Bardi A, Buchanan KE, Goodwin R, Slabu L and Robinson M (2014) Value stability and change during self-chosen life transitions: self-selection versus socialization effects. Journal of Personality and Social Psychology 106, 131-147.

Bergman YS (2017) Ageism in children. In Nelson TD (ed.), Ageism. Stereotyping and Prejudice Against Older People, 2nd Edn. Cambridge, MA: MIT Press, pp. 3-36.

Bigler RS and Liben LS (2006) Developmental intergroup theory: explaining and reducing children's social stereotyping and prejudice. Current Directions in Psychological Science 16, 162-166.

Borg I, Bardi A and Schwartz SH (2015) Does the value circle exist within persons or only across persons? Journal of Personality 85, 151-162.

Börsch-Supan A, Brandt M, Hunkler C, Kneip T, Korbmacher J, Malter F, Schaan B, Stuck S and Zuber S (2013) Data resource profile: the Survey of Health, Ageing and Retirement in Europe (SHARE). International Journal of Epidemiology 42, 992-1001.

Bowen CE and Skirbekk V (2013) National stereotypes of older people's competence are related to older adults' participation in paid and volunteer work. Journals of Gerontology: Psychological Sciences and Social Sciences 68B, 974-983.

Bruckmüller S and Abele AE (2013) The density of the Big Two: how are agency and communion structurally represented? Social Psychology 44, 63-74.

Chang E-S, Kannoth S, Levy S, Wang S-Y, Lee JE and Levy BR (2020) Global reach of ageism on older persons' health: A systematic review. PLoS ONE 15. https://doi.org/10.1371/journal.pone.0220857.

Chopik W and Giasson H (2017) Age differences in explicit and implicit age attitudes across the life span. The Gerontologist 57, 169-177.

Crandall CE and Eshleman A (2003) A justification-suppression model of the expression and experience of prejudice. Psychological Bulletin 129, 414-446.

Crandall CE, Bahns AJ, Warner R and Schaller M (2011) Stereotypes as justifications of prejudice. Personality and Social Psychology Bulletin 37, 1488-1498.

Cuddy AJC, Norton MI and Fiske ST (2005) This old stereotype: the pervasiveness and persistence of the elderly stereotype. Journal of Social Issues 61, 267-285.

Delhey J, Boehnke K, Dragolov G, Ignácz ZS, Larsen M, Lorenz J and Koch M (2018) Social cohesion and its correlates: a comparison of Western and Asian societies. Comparative Sociology 17, 426-455.

de Paula Couto MCP and Wentura D (2017) Implicit ageism. In Nelson TD (ed.), Ageism: Stereotyping and Prejudice Against Older People, 2nd Edn. Cambridge, MA: MIT Press, pp. 37-76.

Drury L, Hutchison P and Abrams D (2016) Direct and extended intergenerational contact and young people's attitudes towards older adults. British Journal of Social Psychology 55, 522-543.

European Social Survey (ESS) Round 4 (2008) Data file edition 4.4 (Dataset). Bergen, Norway: Norwegian Social Science Data Services - Data Archive and Distributor of ESS Data.

Falanga R, de Caroli ME and Sagone E (2015) Are value priorities predictors of prejudice? A study with Italian adolescents. Procedia - Social and Behavioral Sciences 191, 296-301.

Feather NT and McKee IR (2011) Values and prejudice: predictors of attitudes towards Australian Aborigines. Australian Journal of Psychology 60, 80-90.

Florez IA, Schulenberg SE, Lair EC, Wilson KG and Johnson KA (2019) Understanding meaning and racial prejudice: examining self-transcendence and psychological inflexibility in a sample of White college students. Journal of Contextual Behavioral Science 12, 1-6.

Gelfand MJ (2012) Culture's constraints: international differences in the strength of social norms. Current Directions in Psychological Science 21, 420-424.

Georgantzi N (2018) The European Union's approach towards ageism. In Ayalon L and Tesch-Römer C (eds), Contemporary Perspectives on Ageism. Cham, Switzerland: Springer Open, pp. 341-368.

Greenberg J, Pyszczynski T and Solomon S (1986) The causes and consequences of a need for self-esteem: a terror management theory. In Baumeister RF (ed.), Public and Private Self. New York, NY: Springer, pp. 189-212.

Heine SJ and Hamamura T (2007) In search of East Asian self-enhancement. Personality and Social Psychology Review 11, 4-27. 
Inglehart R, Haerpfer C, Moreno A, Welzel C, Kizilova K, Diez-Medrano, et al. (eds) (2014) World Values Survey: Round Six - country-pooled data file version (Dataset). Madrid: JD Systems Institute. Available at www.worldvaluessurvey.org/WVSDocumentationWV6.jsp.

Iversen TN, Larsen L and Solem PE (2009) A conceptual analysis of ageism. Nordic Psychology 61, 4-22.

Kessler E-M and Schwender C (2012) Giving dementia a face? The portrayal of older people with dementia in German weekly news magazines between the years of 2000 and 2009. Journals of Gerontology: Psychological Sciences and Social Sciences 67B, 261-270.

Kornadt AE and Rothermund K (2011) Contexts of aging: assessing evaluative age stereotypes in different life domains. Journals of Gerontology: Psychological Sciences and Social Sciences 66B, 547-556.

Kroh M, Kühne S, Siegers R and Belcheva V (2018) SOEP-Core - Documentation of Sample Sizes and Panel Attrition (1984 Until 2016) (SOEP Survey Papers 480: Series C). Berlin: DIW/SOEP. Available at https://www.diw.de/documents/publikationen/73/diw_01.c.579464.de/diw_ssp0480.pdf.

Lamont RA, Swift HJ and Abrams D (2015) A review and meta-analysis of age-based stereotype threat: negative stereotypes, not facts, do the damage. Psychology and Aging 30, 180-193.

Lev S, Wurm S and Ayalon L (2018) Origins of ageism at the individual level. In Ayalon L and Tesch-Römer C (eds), Contemporary Perspectives on Ageism. Cham, Switzerland: Springer Open, pp. 51-72.

Levy B (2009) Stereotype embodiment: a psychological approach to aging. Current Directions in Psychological Science 18, 332-336.

Levy BR and Banaji MR (2002) Implicit ageism. In Nelson TD (ed.), Ageism. Stereotyping and Prejudice Against Older Persons. Cambridge, MA: MIT Press, pp. 49-76.

Löckenhoff CE, De Fruyt F, Terracciano A, McCrae RR, De Bolle M, Costa Jr., PT, Aguilar-Vafaie ME, Ahn C-K, Alcalay L, Allik J, Avdeyeva TV and Barbaranelli C (2009) Perceptions of aging across 26 cultures and their culture-level associates. Psychology and Aging 24, 941-954. https://10.1037/a0016901.

Marques S, Mariano J, Mendonça J, De Tavernier W, Hess M, Naegele L, Peixeiro F and Martins D (2020) Determinants of ageism against older adults: A systematic review. International Journal of Environmental Research and Public Health 17, 2560-2582. https://10.3390/ijerph17072560.

Martens A, Goldenberg JL and Greenberg J (2005) A terror management perspective on ageism. Journal of Social Issues 61, 223-239.

Montepare JM and Zebrowitz LA (2002) A social-developmental view of ageism. In Nelson TD (ed.), Ageism. Stereotyping and Prejudice Against Older Persons. Cambridge, MA: MIT Press, pp. 77-128.

Muthén B and Asparouhov T (2012) Bayesian structural equation modelling: a more flexible representation of substantive theory. Psychological Methods 17, 313-335.

Muthén B and Muthén L (2017) Mplus Version 8 (Software). Los Angeles, CA: Muthén \& Muthén.

Ng R, Heather GA, Trentalange M, Monin JK and Levy BR (2015) Increasing negativity of age stereotypes across 200 years: evidence from a database of 400 million words. PLOS ONE 10. https://doi. org/10.1371/journal.pone.0117086.

North MS and Fiske ST (2012) An inconvenienced youth? Ageism and its potential intergenerational roots. Psychological Bulletin 138, 982-997.

North MS and Fiske ST (2013) Act your (old) age: prescriptive, ageist biases over succession, consumption, and identity. Personality and Social Psychology Bulletin 39, 720-734.

North MS and Fiske ST (2015) Modern attitudes toward older adults in the aging world: a cross-cultural meta-analysis. Psychological Bulletin 141, 993-1021.

North MS and Fiske ST (2017) Succession, consumption, and identity: Prescriptive ageism domains. In Nelson TD (ed.), Ageism. Stereotyping and Prejudice Against Older People. Cambridge, MA: The MIT Press, 2nd ed., pp. 77-95.

Pereira C, Vala J and Costa-Lopes R (2010) From prejudice to discrimination: the legitimizing role of perceived threat in discrimination against immigrants. European Journal of Social Psychology 40, 12311250.

Peterson L and Ralston M (2017) Valued elders or societal burden: cross-national attitudes toward older adults. International Sociology 32, 731-754.

Pettigrew TF and Meertens RW (1995) Subtle and blatant prejudice in western Europe. European Journal of Social Psychology 25, 57-75.

Requena MdC, Swift HJ, Naegele L, Zwamborn M, Metz S, Bosems WPH and van Hoof J (2018) Educational methods using intergenerational interaction to fight ageism. In Ayalon $\mathrm{L}$ and 
Tesch-Römer C (eds), Contemporary Perspectives on Ageism. Cham, Switzerland: Springer Open, pp. 383-402.

Schwartz SH (2003) A proposal for measuring value orientations across nations. In Questionnaire Package of the European Social Survey, pp. 259-319. Available at https://pdfs.semanticscholar.org/376a/ d809f1313cb41dfcffa8bd180949c273f8c2.pdf.

Schwartz SH (2006) A theory of cultural value orientations: explication and applications. Comparative Sociology 5, 137-182.

Schwartz SH (2008) The 7 Schwartz cultural value orientation scores for 80 countries (Data). Available at https://doi.org/10.13140/RG.2.1.3313.3040.

Schwartz SH (2012) An overview of the Schwartz theory of basic values. Online Readings in Psychology and Culture 2. http://dx.doi.org/10.9707/2307-0919.1116.

Schwartz SH (2014) Rethinking the concept and measurement of societal culture in light of empirical findings. Journal of Cross-cultural Psychology 45, 5-13.

Shrout PE and Bolger N (2002) Mediation in experimental and nonexperimental studies: new procedures and recommendations. Psychological Methods 7, 422-445.

Stanciu A and Vauclair C-M (2018) Stereotype accommodation: a socio-cognitive perspective on migrants' cultural adaptation. Journal of Cross-cultural Psychology 49, 1027-1047.

Swift HJ, Abrams D, Marques S, Vauclair C-M, Bratt C and Lima M-L (2018) Ageism in the European region: findings from the European Social Survey. In Ayalon L and Tesch-Römer C (eds), Contemporary Perspectives on Ageism. Cham, Switzerland: Springer Open, pp. 441-460.

Tajfel H and Turner J (1979) An integrative theory of intergroup conflict. In Austin W and Worchel S (eds), The Social Psychology of Intergroup Relations. Monterey, CA: Brooks/Cole, pp. 33-47.

United Nations Development Programme (2019) Human development data (1990-2017) (Data). Available at http://hdr.undp.org/en/data.

Van Berkel L, Crandall CS, Eidelman S and Blanchar JC (2015) Hierarchy, dominance, and deliberation: egalitarian values require mental effort. Personality and Social Psychology Bulletin 41, 1207-1222.

Vauclair C-M, Marques S, Lima ML, Bratt C, Swift HJ and Abrams D (2014) Subjective status of older people across countries: the role of modernization and employment. Journals of Gerontology: Psychological Sciences and Social Sciences 70B, 650-660.

Vauclair C-M, Hanke K, Huang L-L and Abrams D (2017) Are Asian cultures really less ageist than Western ones? It depends on the questions asked. International Journal of Psychology 52, 136-144.

Voss P, Bodner E and Rothermund K (2018) Ageism: the relationship between age stereotypes and age discrimination. In Ayalon L and Tesch-Römer C (eds), Contemporary Perspectives on Ageism. Cham, Switzerland: Springer Open, pp. 11-31.

Wang L (2003) Race as proxy: situational racism and self-fulfilling stereotypes. DePaul Law Review 53, 1013-1109.

World Bank (2019) Age dependency ratio, old (\% of working-age population) (Data). Available at https:// data.worldbank.org/indicator/SP.POP.DPND.OL.

Yzerbyt VY and Demoulin S (2012) Metacognition in stereotypes and prejudice. In Brinol P and DeMarree KG (eds), Social Metacognition. New York, NY: Psychology Press, pp. 243-262.

Zhang X, Xing C, Guan Y, Song X, Melloy R, Wang R and Jin X (2016) Attitudes toward older adults: A matter of cultural values or personal values?. Psychology and Aging 31, 89-100. https://dx.doi.org/10. 1037/pag0000068.

Cite this article: Stanciu A (2022). Value systems as motivational forces for the suppression of ageism towards older people amongst young adults: an analysis across countries. Ageing \& Society 42, 868-895. https://doi.org/10.1017/S0144686X20001257 